Neurodegenerative Dis 2011;8:386-396

DOI: $\underline{10.1159 / 000324159}$
Received: July 22, 2010

Accepted after revision: January 5, 2011

Published online: February 23, 2011

\title{
Altered Expression of Myogenic Regulatory Factors in the Mouse Model of Amyotrophic Lateral Sclerosis
}

\author{
Raquel Manzano ${ }^{\mathrm{a}}$ Janne M. Toivonen ${ }^{\mathrm{a}}$ Sara Oliván $^{\mathrm{a}}$ Ana C. Calvo ${ }^{\mathrm{a}}$ \\ Maria Moreno-lgoa ${ }^{a}$ Maria J. Muñoz ${ }^{\text {a }}$ Pilar Zaragoza $^{a}$ \\ Alberto García-Redondo ${ }^{b}$ Rosario Osta ${ }^{a}$ \\ a LAGENBIO-I3A, Aragón Institute of Health Sciences (IACS), Universidad de Zaragoza, Zaragoza, and \\ bServicio de Neurología, Unidad de ELA, CIBERER U-723, Instituto de Investigación Sanitaria Hospital 12 de Octubre \\ (i+12), Madrid, Spain
}

\section{Key Words}

Amyotrophic lateral sclerosis $\cdot$ Motor neuron disease $\cdot$

Myogenic regulatory factor $\cdot$ Muscle $\cdot$ Denervation

\begin{abstract}
Background: In the superoxide dismutase 1 (SOD1)-G93A mouse model of amyotrophic lateral sclerosis (ALS), skeletal muscle is a key target of mutant SOD1 toxicity. However, the expression of factors that control the regenerative potential of the muscle is unknown in this model. Objective: To characterize the expression of satellite cell marker Pax7 and myogenic regulatory factors (MRF) in skeletal muscle of SOD1G93A mice at different stages of the disease. Methods: The expressions of Pax7, Myod1, Myf5 and myogenin (Myog) were determined by quantitative real-time PCR and by Western blotting from the grouped gastrocnemius, quadriceps and soleus muscles of SOD1-G93A mice at presymptomatic, symptomatic and terminal stages of the disease, and from surgically denervated wild-type gastrocnemius muscles. Results: Pax7 mRNA and MYF5 protein were upregulated in presymptomatic mice, coinciding with increased muscle damage marker Rrad and chemokine C Cl5. All MRF transcripts and most proteins (excluding MYOG) were increased, starting from 3 months of age, simultaneously with
\end{abstract}

\section{KARGER}

Fax +4161306 1234

E-Mail karger@karger.ch

www.karger.com
(C) 2011 S. Karger AG, Basel

$1660-2854 / 11 / 0085-0386 \$ 38.00 / 0$

Accessible online at:

www.karger.com/ndd increased expression of denervation marker Chrna1. However, in the terminal stage, no protein increase was evident for Pax7 or any of the MRF despite the increased mRNA levels. The transcripts for chemokine $\mathrm{Ccl} 2$ and chemokine receptor $C x c r 4$ were increased starting from the onset of symptoms. Conclusions: The characterization of $\mathrm{Pax} 7$ and MRF in SOD1-G93A mice reveals a progressive induction of the myogenic program at the RNA level, but a blunted protein level response at late stages of the disease. Altered posttranscriptional and posttranslational mechanisms likely to operate, as well as the potential role of chemokine signaling in mutant SOD1 muscle, are discussed. Copyright $\odot 2011$ S. Karger AG, Basel

\section{Introduction}

Amyotrophic lateral sclerosis (ALS) is a fatal paralytic motor neuron (MN) disease characterized by progressive muscle weakness caused by gradual degeneration of upper and lower motor neurons [1]. Approximately $10 \%$ of ALS cases are familial (FALS), and one fifth of these are caused by mutations in the gene encoding antioxidant enzyme $\mathrm{Cu} / \mathrm{Zn}$ superoxide dismutase 1 (SOD1) [2]. This suggests that oxidative stress is one of the key mecha- 
nisms that underlie ALS pathogenesis. Transgenic mouse models of FALS have been instrumental in shedding light on pathophysiological and molecular aberrations in human ALS patients [3]. The most frequently used model of FALS is a ubiquitous overexpressor of human SOD1 that carries a glycine-to-alanine substitution at residue 93 (SOD1-G93A) [4] and results in toxic gain of SOD1 function [5]. Although the precise cellular mechanisms of mutant SOD1 (mSOD1) toxicity remain unknown, SOD1G93A mice develop pathological and clinical features closely resembling human ALS [6]. The primary trigger for the pathogenic events is thought to be the interruption of the nerve connection at the neuromuscular junction (NMJ), which precedes axonal degeneration and death of MN cell bodies [7-10]. Debate still continues as to what extent the muscle denervation in ALS models is of neuronal origin: neuron-restricted expression of the mSOD1 does not replicate the hallmarks of the disease $[11,12]$, although this may depend on the mSOD1 expression level [13]. On the other hand, the non-cell-autonomous contribution to MN degeneration by non-neural cells (such as microglia, astrocytes and muscle) is evident [14], and suggests that alterations in multiple cell types act synergistically to exacerbate the disease.

Involvement of skeletal muscle in ALS pathophysiology was first inferred from early muscle hypermetabolism in mSOD1 mice and in human patients [15-17]. Experimentally induced muscle hypermetabolism dismantles $\mathrm{NMJ}$ in wild-type mice as well as it promotes disease progression in $\mathrm{mSOD} 1$ animals [18]. Additionally, a denervation-promoting factor, Nogo-A, is upregulated in ALS skeletal muscle $[19,20]$. Recent studies have demonstrated that skeletal muscle-specific mSOD1 overexpression is sufficient to induce oxidative damage and trigger ALS symptoms [21] as well as MN degeneration [22]. Collectively, these studies suggest that early changes in ALS muscle may promote denervation.

Postmitotic skeletal muscle fibers show a great degree of plasticity in response to exercise, damage and disease [23]. The capacity for tissue repair derives largely from activation of satellite cells (SC), mononuclear stem cells that reside beneath the basal membrane of the mature muscle fiber [24, 25]. Pax7 is a paired-box transcription factor essential for the survival, maintenance and myogenic potential of SC $[26,27]$. Muscle growth and differentiation are regulated by a complex interaction between myogenic regulatory factors (MRF) such as Myf5, Myod1 and myogenin (Myog), which specifically activate the production of key muscle genes [28]. Following muscle injury, quiescent Pax7-positive SC migrate to the site of damage, upregulate the myogenic determinants $M y f 5$ and Myod1 and reenter the cell cycle [29-31]. These activated myoblasts subsequently downregulate Pax7 and induce $M y o g$ to initiate terminal differentiation. This is followed by fusion with other SC or with damaged myofibers, cell cycle exit and progressive loss of MRF expression.

Transcriptional induction of MRF upon surgical denervation is well described [32-36]. However, although the denervation of NMJ in ALS is evident, potential alterations in myogenic regulation in FALS models remain unexplored. Skeletal muscle tissue in mSOD1 mice is not only affected by denervation but also suffers from nerveindependent loss of muscle homeostasis [21,37]. Muscleautonomous mSOD1 toxicity may limit the capacity of mutant muscle to regenerate, and altered expression of SC markers (such as $\mathrm{Pax} 7$ ) or MRF could serve as early indicators of such a process. Muscle regeneration may also be affected by recruitment of muscle-resident or circulating myogenic progenitor cells other than SC [38-42]. Directional cell migration to muscle may be enhanced by the action of secreted chemotactic cytokines (chemokines), some of which are upregulated at least in the circulation and the cerebrospinal compartment of ALS patients [4349]. Intriguingly, many chemokines and their receptors are increased during regenerative myogenesis in vivo, and some have been shown to stimulate myoblast migratory activity [50,51]. However, chemokine expression in ALS muscle remains unexplored.

Clinical and pathological similarities between sporadic and inherited ALS have created the anticipation that models of FALS may provide insight into mechanisms of both forms of the disease and, ultimately, contribute to therapeutic strategies in humans. Skeletal muscle is regarded as one of the most promising targets for therapeutic interventions including molecular therapy, although considerable obstacles remain to be overcome as well [23]. To elucidate potential alterations to myogenic factors in mSOD1-expressing muscle, we systematically investigated transcript and protein level changes in Pax7 and MRF at different ages of SOD1-G93A mice. Additionally, we looked for transcriptional alterations in muscle chemokine signaling, which may provide alternative cues for myogenic precursor recruitment in ALS.

\section{Materials and Methods}

All experimental procedures were approved by the ethics committee of the institution and followed the international guidelines for the use of laboratory animals. The transgenic mice B6SJL$\mathrm{Tg}(\mathrm{SOD} 1-\mathrm{G} 93 \mathrm{~A}) 1 \mathrm{Gur} / \mathrm{J}$ [4] expressing a high copy number of the 
G93A mutant form of human SOD1 were purchased from The Jackson Laboratory (Bar Harbor, Me., USA) and were housed under a 12 -hour light $/ 12$-hour dark cycle at $21-23^{\circ} \mathrm{C}$ with a relative humidity of $55 \%$. Food and water were available ad libitum. The transgenic colony was maintained by breeding hemizygous SOD1-G93A males with B6SJL wild-type female littermates. The genotypes were determined from tail samples as described in the Jackson Laboratory protocol. Heterozygous male mice and their nontransgenic male littermates were used for all experiments.

\section{Surgical Denervation}

Six male wild-type (nontransgenic) mice of the B6CLJ strain were anesthetized (pentobarbital $30 \mathrm{mg} \cdot \mathrm{kg}^{-1}$, i.p.) at the age of 60 days, and muscle denervation was performed unilaterally in the right hindlimb by extracting a $5-\mathrm{mm}$ segment of the sciatic nerve through an incision in the mid-posterolateral area of the thigh. The left limb was left intact and served as a control. The incision was closed with silk sutures and washed daily with antibacterial solution to prevent infection. The absence of the toe-spreading reflex was confirmed daily. Two weeks after surgical denervation (at the age of 74 days), the animals were sacrificed by cervical dislocation and the gastrocnemius muscles were dissected and frozen immediately in liquid nitrogen.

\section{Extraction of Muscle Samples}

Hemizygous SOD1-G93A males and age-matched nontransgenic wild-type control males were sacrificed by cervical dislocation at postnatal (P) age of P40, P60, P90 or P120 days. At each age, 5 animals per genotype were used. Quadriceps, gastrocnemius and soleus muscles from both hindlimbs were individually dissected, snap frozen in liquid nitrogen, and then temporarily stored at $-70^{\circ} \mathrm{C}$. The quadriceps muscle group (vastus lateralis, vastus medialis and vastus intermedius) and gastrocnemius muscles (medial and lateral) both consist of approximately $60 \%$ fastfatigable (FF) fibers, 35\% fast fatigue-resistant fibers and 5\% slow (S) fibers, whereas the soleus is composed of $58 \% \mathrm{~S}$ fibers and $42 \%$ fast fatigue-resistant fibers [52]. This group of muscles was selected to ensure enough material for both RNA and protein studies, and because it consists of muscles with a high percentage of FF fibers or $\mathrm{S}$ fibers, which are most vulnerable or resistant to denervation in the SOD1-G93A model, respectively [8-10]. The dissected muscles from each mouse were pooled and pulverized in a cold mortar with liquid nitrogen. The powdered tissue was divided equally in two prechilled tubes, one for RNA extraction and the other one for protein extraction.

\section{Quantification of mRNA Expression}

For total RNA extraction, powdered muscle tissue was further homogenized using a PRO200 homogenizer (PRO Scientific Inc.) and then processed according to the TRIzol Reagent protocol (Invitrogen). The RNA samples were processed with the Turbo DNAfree kit (Ambion) to eliminate genomic DNA. Reverse transcription was carried out according to the SuperScript ${ }^{\mathrm{TM}}$ First-Strand Synthesis System kit (Invitrogen) using random hexamers with $1 \mu \mathrm{g}$ of template RNA in a final volume of $20 \mu \mathrm{l}$. TaqMan ${ }^{\circledR}$ (Applied Biosystems) probe-based quantitative PCR reactions were performed from $1 \mu \mathrm{l}$ of 1:10 diluted cDNA in a reaction mixture containing $1 \times$ TaqMan Universal PCR Master Mix (No AmpErase ${ }^{\circledR}$ UNG) and $1 \times$ TaqMan primer/probe mix in a final volume of $10 \mu \mathrm{l}$. Triplicate reactions from each cDNA were per- formed in an ABI Prism 7000 Sequence Detection System (Applied Biosystems) using the following thermal cycling parameters: incubation at $95^{\circ} \mathrm{C}$ for $10 \mathrm{~min}$, followed by 40 cycles of $95^{\circ} \mathrm{C}$ for $15 \mathrm{~s}$ and $60^{\circ} \mathrm{C}$ for $1 \mathrm{~min}$. Reaction efficiencies of the primer/ probe sets approached $100 \%$ (see online supplementary table 1 , www.karger.com/doi/10.1159/000324159). In the same conditions, reference gene amplification was performed using TaqMan primer/probe mixtures for three reference genes (18S rRNA, Gapdh and $\beta$-actin). Relative gene expression was determined using the $2^{-\Delta \Delta C t}$ method, where the data are presented as a fold change in gene expression normalized to the reference genes and relative to the nontransgenic age-matched calibrator [53] (online suppl. materials and methods). Analysis of Ccl5 (Mm01302428 m1), Ccl2 (Mm00441242_m1) and Cxcr4 (Mm01292123_m1) transcript levels was carried out in identical reaction conditions but using Applied Biosystems Custom TaqMan Microfluidic Cards and 7900HT Fast Real-Time PCR Systems. Data processing and analysis were carried out as detailed above for the individual reaction assays.

\section{Western Blot Analysis}

The powdered muscle tissue was suspended in ice-cold buffer containing $150 \mathrm{~mm} \mathrm{NaCl}, 50 \mathrm{~mm}$ Tris- $\mathrm{HCl}$ ( $\mathrm{pH} 7.5$ ), 1\% deoxycholate, $0.1 \%$ SDS, $1 \%$ Triton X-100, $1 \mathrm{mM} \mathrm{Na}_{3} \mathrm{VO}_{4}, 1 \mathrm{~mm}$ PMSF, 10 $\mu \mathrm{g} / \mathrm{ml}$ leupeptin/aprotinin and $1 \mu \mathrm{g} / \mathrm{ml}$ pepstatin. The samples were centrifuged at $3,000 \mathrm{rpm}$ at $4^{\circ} \mathrm{C}$ for $10 \mathrm{~min}$, and the total protein in the supernatant fractions was quantified by the BCA method (Sigma-Aldrich). The proteins (60 $\mu$ g per well) were separated by SDS-PAGE alongside molecular weight standards, and subsequently transferred to polyvinylidene fluoride membranes (GE Healthcare) at $100 \mathrm{~V}$ for $1 \mathrm{~h}$ in a transfer buffer containing 25 $\mathrm{mm}$ Tris, $200 \mathrm{~mm}$ glycine and $10 \%$ (v/v) methanol. The membranes were blocked in Tris-buffered saline supplemented with $0.1 \%$ Tween 20 and $5 \%(\mathrm{w} / \mathrm{v})$ powdered skim milk for $1 \mathrm{~h}$ at room temperature and incubated overnight at $4^{\circ} \mathrm{C}$ with a primary antibody diluted in a freshly prepared blocking buffer. The antibody dilutions used were: PAX7 (Ab34360; Abcam) 1:250; MYOD1 (sc304; Santa Cruz Biotechnology Inc.) 1:300; MYOG (sc-576; Santa Cruz Biotechnology) $1 \mu \mathrm{g} / \mathrm{ml}$; MYF5 (sc-302; Santa Cruz Biotechnology 1:200), and GAPDH (sc-25778; Santa Cruz Biotechnology) $1: 5,000$. Subsequently, the membranes were incubated for $1 \mathrm{~h}$ at room temperature in a solution containing the horseradish peroxidase-conjugated secondary antibody (sc-2004; Santa Cruz Biotechnology), diluted 1:5,000 in blocking buffer. Several washes with Tris-buffered saline and $0.1 \%$ Tween 20 were performed after incubation with primary and secondary antibodies. Blots were detected using Western Blotting Luminol Reagent (Santa Cruz Biotechnology) and were exposed to Curix RP2 Plus X-ray film (Agfa). The computer-assisted intensity analysis of the detected bands was performed with the AlphaEaseFC software (Bonsai Technologies Group). The mean value of normalized intensities from SOD1-G93A animals was compared to that of the wild-type mice to obtain a fold change. For standard errors of the mean, each normalized SOD1-G93A value was compared to the normalized mean intensity of the wild type.

\section{Statistics}

Statistics were performed using Statistica 5.0 (Statsoft). Comparisons were carried out by the Student $t$ test, and $p<0.05$ was considered significant. 


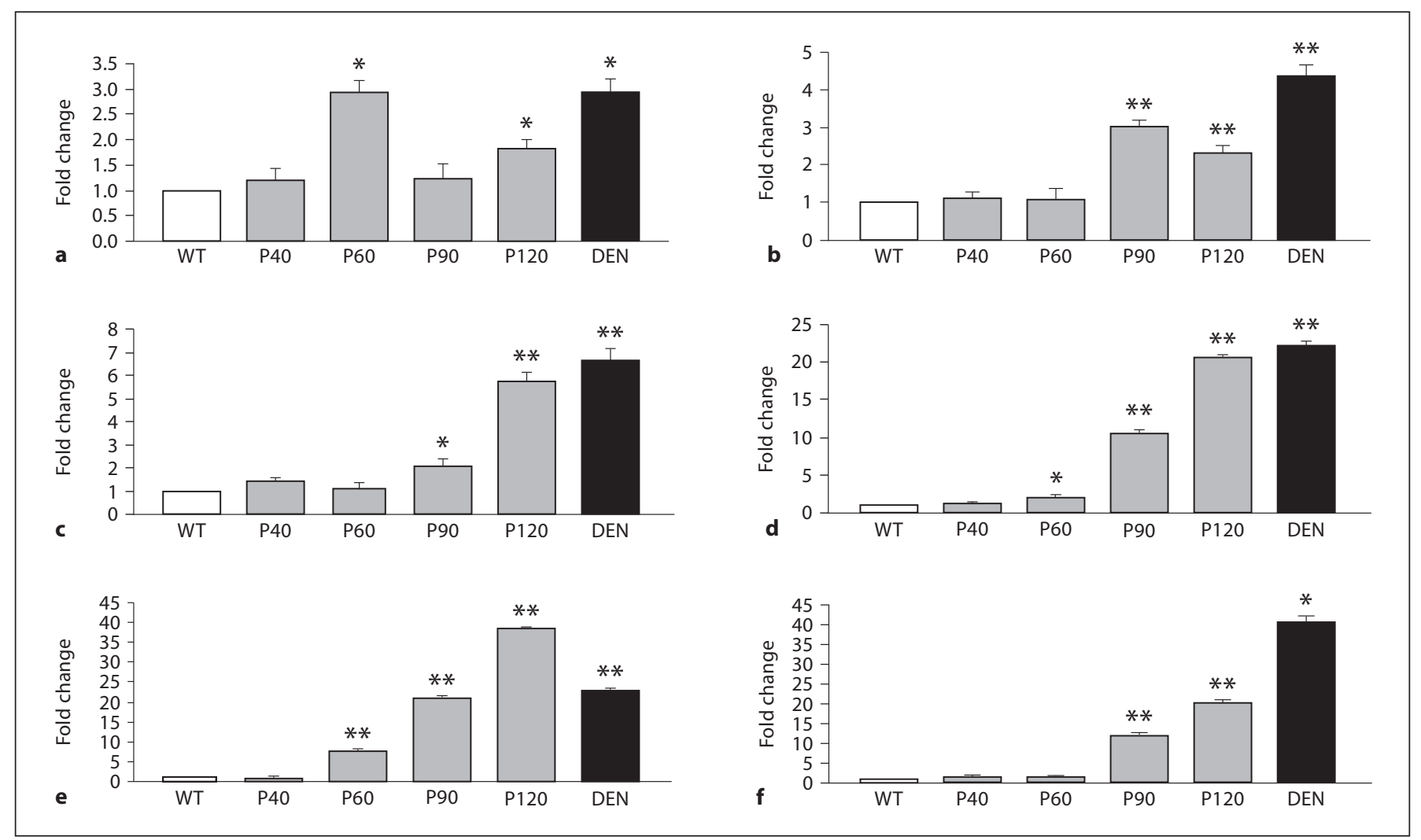

Fig. 1. Upregulation of Pax7, MRF, Rrad and Chrnal transcripts in SOD1-G93A and denervated muscles. The results are shown as fold change in SOD1-G93A animals (grey bars) relative to wildtype littermates (WT; white bars) at each indicated age (P40, P60,
P90 and P120), or relative to the nonoperated limb in denervated mice (DEN; black bars). Error bars: SEM. ${ }^{*} \mathrm{p}<0.05$; ${ }^{*} \mathrm{p}<$ 0.001. a Pax7. b Myf5. c Myod1. d Myog. e Rrad. f Chrnal.

\section{Results}

Transcriptional Upregulation of Pax7 and MRF in mSOD1 Muscles

To gain insight into the regulation of the myogenic process in SOD1-G93A mice at different stages of the disease, quantitative RT-PCR was performed at P40, P60, $\mathrm{P} 90$ and $\mathrm{P} 120$. These time points were selected to monitor changes at early (P40) and late presymptomatic (P60) stages, as well as at the onset of the symptomatic (P90) and terminal stages (P120). Relative expression (fold difference) of Pax7, Myf5, Myod1 and Myog (fig. 1a-d) was determined for each age, using RNA derived from pooled quadriceps, gastrocnemius and soleus muscles of SOD1G93A hemizygotes and their age-matched nontransgenic littermates. In mSOD1-expressing muscle, the production of reactive oxygen species (ROS) is elevated, which in turn activates the expression of Rrad (Ras-related associated with diabetes), an early marker in ALS patients and $\mathrm{mSOD} 1$ mice [37]. Although Rrad is also upregulated by denervation, its transcription precedes that of the 'ROS-insensitive' denervation marker Chrnal (cholinergic receptor, nicotinic, alpha) [37]. Monitoring of Rrad (fig. 1e) enabled us also to estimate the first appearance of the muscle damage before the onset of symptoms. Similarly, the extent of denervation was monitored by induction of Chrnal (fig. 1f) as this receptor is transcriptionally regulated by electrical activity $[32,34,54]$ and not by ROS [37]. To compare the effects of surgical axotomy with those caused by SOD1-G93A mutation, we also performed sciatic denervation on wild-type mice at P60 and analyzed the expression of the above-mentioned factors in the gastrocnemius muscles at P74, 2 weeks after the operation (fig. 1a-f, black bars).

At the early presymptomatic stage of the SOD1-G93A mice (P40), none of the genes under study were significantly affected (fig. 1a-f). Unaltered expression of Rrad and Chrnal at this time point indicates that muscle dam- 

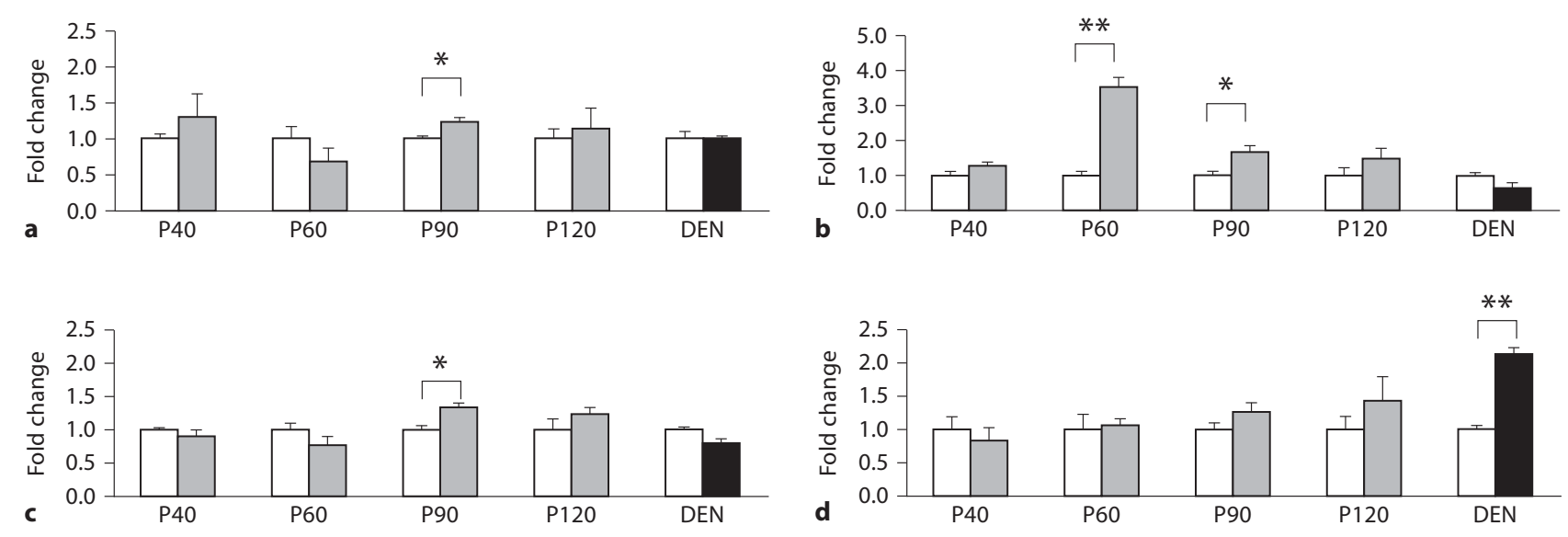

Fig. 2. Protein level regulation of PAX7 and MRF in SOD1-G93A and denervated muscles. The results are shown as fold change in SOD1-G93A animals (grey bars) relative to wild-type littermates (white bars) at each indicated age (P40, P60, P90 and P120), or

age (and associated ROS production) and denervation in SOD1-G93A animals either has not commenced or is minimal, which is consistent with previously reported data $[10,37]$. At the later presymptomatic stage (P60), Pax7 transcript levels were 3 -fold higher than in the nontransgenic controls (fig. 1a). However, Myf5 (fig. 1b) or Myod1 (fig. 1c) were not affected, whereas Myog (fig. 1d) and Rrad (fig. 1e) - but not Chrnal (fig. 1f) - were modestly upregulated. At the onset of ALS-like symptoms in the SOD1-G93A animals (P90), a 3-fold upregulation of Myf5 (fig. 1b), a 2.1-fold upregulation of Myod1 (fig. 1c) and a robust 10.6-fold upregulation of Myog (fig. 1d) was observed, whereas Pax7 mRNA (fig. 1a) was not significantly affected at this stage. Also, a 11.6-fold induction of Chrnal (fig. 1f) was first seen at this age, where the loss of NMJ is already significant. At the onset of the terminal stage (P120), all genes studied were upregulated, ranging from 1.8-fold for Pax7, 2.3-fold for Myf5, 6-fold for Myod1 to 20-fold for Myog. All genes studied were also upregulated in the denervated gastrocnemius muscles of the nontransgenic wild-type mice compared with the intact control muscles from the same animals (fig. 1a-f, black bars). These observations provide the first evidence of a systematic transcriptional activation of the myogenic program in SOD1-G93A animals and suggest a great degree of similarity in the regulation of MRF mRNA in denervated and mSOD1 muscles. However, as observed earlier in mouse models of ALS [37], Rrad was upregulated relative to the nonoperated limb in denervated mice (DEN; black bars). Error bars: SEM. ${ }^{*} \mathrm{p}<0.05 ;{ }^{* *} \mathrm{p}<0.001$. Representative Western blot membranes are shown in online supplementary figure 1. a PAX7. b MYF5. c MYOD1. d MYOG.

earlier than Chrnal, suggesting that mSOD1-mediated oxidative stress in the muscle temporally precedes that caused by denervation.

\section{Blunted Increment of Pax7 and MRF Proteins in mSOD1 Muscles}

Induction of myogenic factor mRNA in SOD1-G93A mice prompted us to investigate whether the increase in Pax7 and MRF transcripts was also reflected in the protein level. Western blot analysis was carried out on the same powdered muscle samples as for the mRNA analysis to eliminate possible individual variation between the animals (see Materials and Methods section). At the early presymptomatic stage ( $\mathrm{P} 40)$, the proteins studied were not significantly altered (fig. 2a-d). After this stage, a rather different picture emerged from the protein level studies of PAX7 and MRF as compared with the transcript data. Despite a significant upregulation of $\operatorname{Pax} 7$ (and to a lesser extent Myog) mRNA at P60, the corresponding protein levels were not increased (fig. 2a, d). In contrast, MYF5 was 3.5-fold upregulated (fig. 2b) despite unaltered Myf5 mRNA levels at this stage. At P90, PAX7 (fig. 2a), MYF5 (fig. 2b) and MYOD1 (fig. 2c) proteins were modestly but significantly upregulated, whereas the increment in MYOG was suggestive but not significant (fig. 2d). Most surprisingly, the uniform increase in MRF mRNA levels at P120 was not reflected at the protein level despite the 2.5-fold, 6-fold and 20-fold increases in 


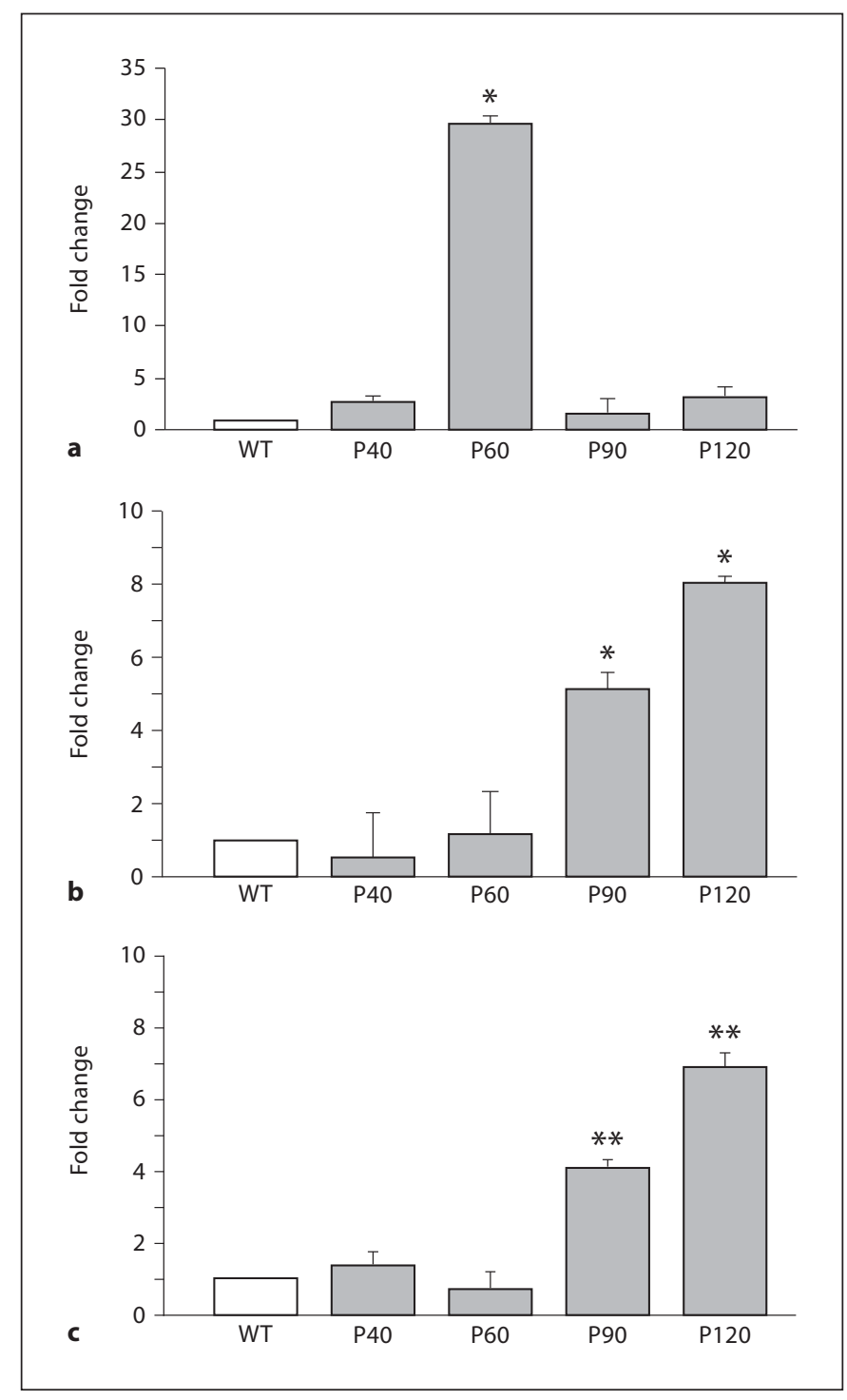

Fig. 3. Altered levels of Ccl5 (a), Ccl2 (b) and Cxcr4 (c) transcripts in SOD1-G93A muscles. The results are shown as fold change in SOD1-G93A animals (grey bars) relative to wild-type littermates (WT; white bars) at each indicated age (P40, P60, P90 and P120). Error bars: SEM. ${ }^{*} \mathrm{p}<0.05 ;{ }^{* *} \mathrm{p}<0.001$.

Myf5, Myod1 and Myog mRNA, respectively. Although MYOG protein showed a tendency to increased relative abundance at advanced stages of the disease, the changes were not significant for any age. In denervated mice (fig. 2a-d, black bars), PAX7, MYF5 and MYOD1 proteins were not significantly altered despite increased mRNA levels. However, MYOG, which was transcriptionally upregulated in denervated muscle, also showed a 2 -fold increase in protein level upon denervation.
These observations reveal both similarities and differences between denervated and SOD1-G93A muscles. PAX7, MYF5 and MYOD1 protein levels were increased at P90 in SOD1-G93A muscles, whereas this was not observed in nontransgenic mice that had been denervated for 2 weeks. The opposite was true for MYOG protein, which was not significantly increased in the mSOD1 muscles at any point but was clearly upregulated upon denervation. Therefore, although transcriptional changes in denervated and mSOD1 muscles are largely consistent (all upregulated), the MYOG protein induction (or lack of it) suggests that differences may exist between SOD1-G93A and denervated muscles.

\section{Altered Expression of Ccl5, Ccl2 and Cxcr4 in SOD1-G93A Muscle}

It is intriguing that $\operatorname{Pax} 7 \mathrm{mRNA}$ was increased in SOD1-G93A muscles already at 60 days of age (fig. 1a). This increase was not likely to be denervation induced because MRF or Chrnal mRNA, which respond transcriptionally to surgical denervation (fig. 1, black bars), were not altered at this stage. This led us to investigate an alternative explanation for the origin of the early increment in Pax7 mRNA expression. Because the Ccl5 chemokine is upregulated in ALS patients [47] and has the potential to stimulate myoblast migratory activity [50], it was regarded as a promising candidate for the recruitment of cells with myogenic potential by the injured mSOD1 muscle. Compared to the age-matched wild-type muscle, Ccl5 mRNA was 29-fold elevated in SOD1-G93A muscles at P60 (fig. 3a), which coincided with a 3 -fold increase in Pax7 transcripts (fig. 1a). At this stage, the expression of Rrad (fig. 1e) was 8-fold higher in SOD1-G93A animals, revealing the commencing muscle damage. These results support the hypothesis that presymptomatic mSOD1-mediated toxicity may cause the recruitment of circulating myogenic cells to the muscle, which may then partly contribute to the Pax7-expressing muscle progenitor pool. To further investigate chemokine-mediated signaling in muscle tissue of SOD1-G93A animals, we looked for mRNA expression of another chemokine, $\mathrm{Ccl} 2$, which is known to be upregulated in ALS $[48,49]$ and during in vitro myogenesis [51]. Additionally, we examined the mRNA expression of $\mathrm{Cxcr} 4$, a chemokine receptor that - together with its ligand, stromal cell-derived factor 1 (SDF-1) - is known to mediate the migration and fusion of muscle cells in vitro and may regulate adult regenerative myogenesis [51]. Unlike Ccl5, levels of which were relatively higher in SOD1-G93A animals only at presymptomatic 
stage P60, both Ccl2 (fig. 3b) and Cxcr4 (fig. 3c) were increased at late stages, starting from the symptomatic stage. These results suggest that, as observed in other tissues of ALS patients, the chemokines $\mathrm{Ccl} 5$ and $\mathrm{Ccl} 2$ are affected in the mSOD1 muscle, although their increased expression is observed at different stages of the disease. Additionally, the results implicate the Cxcr4SDF-1 axis as a potential contributor to SOD1-G93A disease progression.

\section{Discussion}

A direct influence of skeletal muscle tissue on pathogenesis in the mouse models of ALS has recently been demonstrated [21, 22]. Here, we investigated the expression of primary determinants of the regenerative potential of the muscle, i.e. SC function ( $P a x 7)$, myoblast proliferation (Myf5, Myod1) and differentiation (Myog) in the SOD1-G93A model of ALS. A gross increment in MRF species was evident at the symptomatic stage (P90), later than the upregulation of Rrad and in parallel with the induction of denervation marker Chrnal. The drastic increase in MRF transcripts in terminal (P120) SOD1G93A animals did not result in increased levels of MRF proteins, suggesting that the attempted regeneration of SOD1-G93A muscle by MRF transcript upregulation is futile. Presymptomatic increase in Pax7 mRNA coincided with the upregulation of chemokine Ccl5. Furthermore, we demonstrated an increased mRNA expression of chemokine $\mathrm{Ccl} 2$ and chemokine receptor Cxcr4 in SOD1-G93A muscle at later disease stages, which mirrored those of the MRF transcripts. In the following discussion, we will first highlight the similarities and differences between SOD1-G93A and denervated muscle. Then, we will discuss the levels of molecular regulation and posttranscriptional mechanisms that may underline the discrepancies in MRF transcript and protein levels and potentially exacerbate the ALS-associated muscle atrophy. Finally, we will discuss how the increased chemokine expression in mSOD1 muscle may contribute to the availability of myogenic precursors in the mutant muscle.

MRF transcripts, and occasionally proteins, have been shown to be upregulated in response to denervation [3236, 55-58]. Here, the upregulation of MRF transcripts in muscles from denervated limb and their increased relative abundance in SOD1-G93A muscles towards the end of the disease paralleled that of Chrnal, suggesting that increments in Myf5, Myod1 and Myog transcripts are mainly due to decreased electrical stimulation caused by denervation. Based on proportional muscle mass in the pooled gastrocnemius, quadriceps and soleus muscles, the contribution of FF fibers was expected to be close to $60 \%$, although this may have shifted towards more fatigue-resistant types in older SOD1-G93A mice [59]. Therefore, rapid transcriptional induction of MRF probably indicates changes in FF fibers that are innervated by the most vulnerable motor axons in mSOD1 mice $[9,10$, 60]. The MRF studied (but not SC-specific Pax7) are also known to be expressed both in activated myoblasts and in mature myofibers upon denervation $[55,57,61]$. How the described increase in MRF in mSOD1 muscles reflects transcription in SC versus myofibers remains currently unknown.

After 2-week denervation, the MYOG protein level was upregulated in wild-type mice, whereas PAX7, MYF5 and MYOD1 were unaffected. A postdenervation period of 2 weeks was tested here to evaluate the effects of moderately long-term denervation, which we reasoned would better compare with the situation in SOD1-G93A animals. Because MRF expression is strongly induced within days after sciatic denervation and decreases thereafter $[32,34,35]$, it is possible that the time point used here was too late to detect increased MYF5 and MYOD1 proteins. Discrepancies between MRF transcript and protein levels have also been reported earlier [62, 63]. Because of a general lack of simultaneous RNA/protein level studies and a wide variety of techniques and experimental species used, a universally valid MRF response to denervation cannot be stated [64]. However, the fact that Myog transcripts were equally upregulated in denervated and SOD1-G93A muscle, but the MYOG protein increase was only apparent upon denervation, suggests that posttranscriptional regulation of this factor in SOD1-G93A mice may be altered.

Several molecular and pathophysiological alterations may contribute to the discordance between MRF mRNA and protein levels in SOD1-G93A mice. Although MRF proteins were not upregulated at the terminal stage, they were not depleted either (fig. 2). MRF can increase their own transcription and cross-regulate one another's expression [65]. The transcription factor activity of MYOD and MYOG is regulated by phosphorylation [66, 67], relies on hetero-oligomerization with E-proteins [68], and is inhibited by Id1, a negative regulator of $\mathrm{MRF} / \mathrm{E}$-protein oligomerization [69]. Therefore, elevated transcription of MRF mRNA in SOD1-G93A muscles could potentially result from the altered phosphorylation status of the MRF proteins or, alternatively, from the changed balance be- 
tween their oligomerization partners and inhibitors, such as E-proteins and Id1.

Skeletal muscle atrophy induced by pathological conditions involving oxidative damage is characterized by increased proteolysis via the ubiquitin-proteasome pathway [70, 71]. Consistently, the expression of ubiquitin ligases is elevated in human ALS patients and mSOD1 mice [72]. Both MYOD1 and MYOG are targets for proteasomal activity $[73,74]$, and ubiquitin-proteasome-mediated degradation of MYOD1 occurs in several models of skeletal muscle atrophy [75]. Interestingly, ubiquitin ligases in denervated muscle are under direct transcriptional control of MYOG, which therefore may promote the loss of muscle mass as well as differentiation [76]. Muscle-specific expression of insulin-like growth factor 1 attenuates muscle wasting and reduces protein ubiquitination [77], which is associated with increased PAX7 and MYOG protein expression at the terminal stage of SOD1-G93A mice [78]. Therefore, insulin-like growth factor 1 may alleviate the metabolic processes that lead to the blunted protein level expression of these factors in SOD1-G93A muscle. Genetic or pharmaceutical targeting of the proteasome or associated enzymes could possibly serve as a candidate strategy to alleviate SOD1-G93A muscle pathology.

Rather than indicating direct transcriptional activation, increased MRF transcript abundance also derives from posttranscriptional mRNA stabilization. Both Myodl and Myog transcripts are targets of the mRNAstabilizing enzyme $\mathrm{HuR}$, which is elevated in regenerating myofibers in vivo [79]. Under endoplasmic reticulum (ER) stress, global changes in transcript abundance are largely controlled by mRNA stability. Although a possible contribution of ER stress to the pathobiology of the ALS muscle remains unexplored, it has been shown to take place in affected neurons of human ALS patients and mSOD1 models [80]. Equally, RNA oxidation occurs in neurons of both ALS patients and mice overexpressing mSOD1 [81]. Because mRNA stabilization under ER stress [82] and mRNA oxidation in general [83] are associated with decreased protein translation, they may have a role in the observed disparity between the MRF transcripts and their corresponding proteins in SOD1-G93A muscle.

Besides the regulation of MRF at the late disease stages, a discordance was observed between Pax7 and Myf5 transcript and protein levels at the presymptomatic stage. Pax7 mRNA but not protein was increased at P60, whereas $M y f 5$ was only increased in protein level (fig. 1,2). This inconsistency does not derive from muscle sample varia- tion as the same frozen tissue was used for both RNA and protein experiments (see Materials and Methods section). Although further experiments are required to formally address these observations, they may also be linked. Pax7 has recently been shown to be a target of the muscle-specific microRNA miR-1 and miR-206 [84], which are upregulated in $\mathrm{mSOD} 1$ mice [85]. Inhibition of these microRNA increases the PAX7 protein level in vivo and inhibits differentiation [84]. MYF5 potently upregulates these microRNA in developmental myogenesis [86] and may therefore inhibit Pax7 mRNA translation. On the other hand, experiments on synchronized myoblasts have shown that MYF5 protein abundance is regulated by the cell cycle and that the variations in protein level are largely independent of those of $M y f 5$ mRNA, indicating posttranslational control $[87,88]$. This property of $M y f 5$ regulation may contribute to the increased MYF5 protein level despite a lack of transcriptional increase at P60. More detailed analysis is warranted to test these hypotheses on mSOD1 muscle in vivo.

Within healthy skeletal muscle, the quiescent SC number largely remains constant. The relative increase in presymptomatic Pax7 expression in SOD1-G93A muscle could indicate denervation-independent SC renewal/activation or, alternatively, recruitment of Pax7-expressing cells by muscle from other stem cell niches. Myogenic precursor recruitment could potentially be enhanced by chemokines such as $\mathrm{Ccl} 5$, which is upregulated in ALS patients [47]. Ccl5 can stimulate myoblast migratory activity [50], and its transcripts were markedly increased at the presymptomatic stage in SOD1-G93A mice (fig. 3a). Increases at the symptomatic and terminal stages of the disease in chemokine Ccl2 (fig. 3b), also increased in ALS patients [48, 49], and in chemokine receptor Cxcr4 (fig. 3c) provide further support for altered chemokine-mediated signaling in SOD1-G93A muscles. Cxcr4 is expressed in numerous adult stem cells [89], and its ligand, SDF-1, is known to be released from regenerating muscle to attract CXCR4-positive cells [90]. Although these findings are only correlative at this point, they encourage further experiments investigating the nature and regulation of potential myogenic precursor recruitment by chemokines in SOD1-G93A.

To conclude, we described the induction of the myogenic program in the course of the disease in SOD1-G93A mice and revealed both denervation-dependent and -independent effects on Pax7 and MRF expression. These findings encourage further studies on the myogenic process in ALS and indicate that some caution may be required when data are interpreted solely based on tran- 
script abundance. The blunted protein level accumulation of MRF described here should also guide future research in the evaluation of posttranscriptional and posttranslational mechanisms regulating myogenesis in mSOD1 muscles. Furthermore, research aiming at a detailed understanding of chemokine-mediated signaling in affected ALS muscles may help to improve the delivery of myogenic precursors to muscle tissue, which is of considerable interest to those working on therapeutic aspects of ALS.

\section{Acknowledgments}

We would like to thank Ana Pérez (CIMA, University of Navarra, Spain) for the MYF5 antibody. This study was supported by grants PI071133 and PI071283 from the National Health Institute Carlos III (ISCIII) of Spain, PIPAMER 08/08 and 09/09 from the Aragón Institute of Health Sciences, NDG07/07 from the Agencia Pedro Laín Entralgo Comunidad de Madrid, and the Project 'Tú eliges: tú decides' from Caja de Ahorros de Navarra in Spain.

\section{References}

1 Cleveland DW, Rothstein JD: From Charcot to Lou Gehrig: deciphering selective motor neuron death in ALS. Nat Rev Neurosci 2001;2:806-819.

-2 Rosen DR: Mutations in Cu/Zn superoxide dismutase gene are associated with familial amyotrophic lateral sclerosis. Nature 1993; 364:362.

3 Julien JP, Kriz J: Transgenic mouse models of amyotrophic lateral sclerosis. Biochim Biophys Acta 2006;1762:1013-1024.

-4 Gurney ME: Transgenic-mouse model of amyotrophic lateral sclerosis. N Engl J Med 1994;331:1721-1722.

5 Yim MB, Kang JH, Yim HS, Kwak HS, Chock PB, Stadtman ER: A gain-of-function of an amyotrophic lateral sclerosis-associated $\mathrm{Cu}, \mathrm{Zn}$-superoxide dismutase mutant: an enhancement of free radical formation due to a decrease in $\mathrm{K}_{\mathrm{m}}$ for hydrogen peroxide. Proc Natl Acad Sci USA 1996;93:5709-5714.

6 Ripps ME, Huntley GW, Hof PR, Morrison JH, Gordon JW: Transgenic mice expressing an altered murine superoxide dismutase gene provide an animal model of amyotrophic lateral sclerosis. Proc Natl Acad Sci USA 1995;92:689-693.

7 Dupuis L, Loeffler JP: Neuromuscular junction destruction during amyotrophic lateral sclerosis: insights from transgenic models. Curr Opin Pharmacol 2009;9:341-346.

$\checkmark 8$ Fischer LR, Culver DG, Tennant P, Davis AA, Wang M, Castellano-Sanchez A, Khan J, Polak MA, Glass JD: Amyotrophic lateral sclerosis is a distal axonopathy: evidence in mice and man. Exp Neurol 2004; 185:232240.

-9 Frey D, Schneider C, Xu L, Borg J, Spooren W, Caroni P: Early and selective loss of neuromuscular synapse subtypes with low sprouting competence in motoneuron diseases. J Neurosci 2000;20:2534-2542.

10 Hegedus J, Putman CT, Gordon T: Time course of preferential motor unit loss in the SOD1 G93A mouse model of amyotrophic lateral sclerosis. Neurobiol Dis 2007;28:154164.
11 Lino MM, Schneider C, Caroni P: Accumulation of SOD1 mutants in postnatal motoneurons does not cause motoneuron pathology or motoneuron disease. J Neurosci 2002; 22:4825-4832.

12 Pramatarova A, Laganière J, Roussel J, Brisebois K, Rouleau GA: Neuron-specific expression of mutant superoxide dismutase 1 in transgenic mice does not lead to motor impairment. J Neurosci 2001;21:3369-3374.

-13 Jaarsma D, Teuling E, Haasdijk ED, de Zeeuw CI, Hoogenraad CC: Neuron-specific expression of mutant superoxide dismutase is sufficient to induce amyotrophic lateral sclerosis in transgenic mice. J Neurosci 2008; 28:2075-2088.

14 Boillée S, vande Velde C, Cleveland DW: ALS: a disease of motor neurons and their nonneuronal neighbors. Neuron 2006;52: 39-59.

-15 Bouteloup C, Desport JC, Clavelou P, Guy N, Derumeaux-Burel H, Ferrier A, Couratier P: Hypermetabolism in ALS patients: an early and persistent phenomenon. J Neurol 2009; 256:1236-1242.

16 Desport JC, Preux PM, Magy L, Boirie Y, Vallat JM, Beaufrère B, Couratier P: Factors correlated with hypermetabolism in patients with amyotrophic lateral sclerosis. Am J Clin Nutr 2001;74:328-334.

-17 Dupuis L, Oudart H, René F, Gonzalez de Aguilar JL, Loeffler JP: Evidence for defective energy homeostasis in amyotrophic lateral sclerosis: benefit of a high-energy diet in a transgenic mouse model. Proc Natl Acad Sci USA 2004;101:11159-11164.

18 Dupuis L, Gonzalez de Aguilar JL, EchanizLaguna A, Eschbach J, René F, Oudart H, Halter B, Huze C, Schaeffer L, Bouillaud F, Loeffler JP: Muscle mitochondrial uncoupling dismantles neuromuscular junction and triggers distal degeneration of motor neurons. PLoS One 2009;4:e5390.

19 Jokic N, Gonzalez de Aguilar JL, Dimou L, Lin S, Fergani A, Ruegg MA, Schwab ME, Dupuis L, Loeffler JP: The neurite outgrowth inhibitor Nogo-A promotes denervation in an amyotrophic lateral sclerosis model. EMBO Rep 2006;7:1162-1167.
20 Jokic N, Gonzalez de Aguilar JL, Pradat PF, Dupuis L, Echaniz-Laguna A, Muller A, Dubourg O, Seilhean D, Hauw JJ, Loeffler JP, Meininger V: Nogo expression in muscle correlates with amyotrophic lateral sclerosis severity. Ann Neurol 2005;57:553-556.

21 Dobrowolny G, Aucello M, Rizzuto E, Beccafico S, Mammucari C, Boncompagni S, Belia S, Wannenes F, Nicoletti C, del Prete Z, Rosenthal N, Molinaro M, Protasi F, Fano G, Sandri M, Musaro A: Skeletal muscle is a primary target of SOD1G93A-mediated toxicity. Cell Metab 2008;8:425-436.

22 Wong M, Martin LJ: Skeletal muscle-restricted expression of human SOD1 causes motor neuron degeneration in transgenic mice. Hum Mol Genet 2010;19:2284-2302.

23 Tedesco FS, Dellavalle A, Diaz-Manera J, Messina G, Cossu G: Repairing skeletal muscle: regenerative potential of skeletal muscle stem cells. J Clin Invest 2010;120:11-19.

24 le Grand F, Rudnicki M: Satellite and stem cells in muscle growth and repair. Development 2007;134:3953-3957.

25 Mauro A: Satellite cell of skeletal muscle fibers. J Biophys Biochem Cytol 1961;9:493495.

26 Seale P, Sabourin LA, Girgis-Gabardo A, Mansouri A, Gruss P, Rudnicki MA: Pax7 is required for the specification of myogenic satellite cells. Cell 2000;102:777-786.

27 Zammit PS, Relaix F, Nagata Y, Ruiz AP, Collins CA, Partridge TA, Beauchamp JR: Pax7 and myogenic progression in skeletal muscle satellite cells. J Cell Sci 2006;119:1824-1832.

- 28 Rudnicki MA, le Grand F, McKinnell I, Kuang S: The molecular regulation of muscle stem cell function. Cold Spring Harb Symp Quant Biol 2008;73:323-331.

29 Cooper RN, Tajbakhsh S, Mouly V, Cossu G, Buckingham M, Butler-Browne GS: In vivo satellite cell activation via Myf5 and MyoD in regenerating mouse skeletal muscle. J Cell Sci 1999;112:2895-2901.

30 Smith CK 2nd, Janney MJ, Allen RE: Temporal expression of myogenic regulatory genes during activation, proliferation, and differentiation of rat skeletal muscle satellite cells. J Cell Physiol 1994;159:379-385. 
-31 Yablonka-Reuveni Z, Rivera AJ: Temporal expression of regulatory and structural muscle proteins during myogenesis of satellite cells on isolated adult rat fibers. Dev Biol 1994;164:588-603.

- 32 Buonanno A, Apone L, Morasso MI, Beers R, Brenner HR, Eftimie R: The MyoD family of myogenic factors is regulated by electrical activity: isolation and characterization of a mouse Myf-5 cDNA. Nucleic Acids Res 1992; 20:539-544.

33 Duclert A, Piette J, Changeux JP: Influence of innervation of myogenic factors and acetylcholine receptor alpha-subunit mRNAs. Neuroreport 1991;2:25-28.

-34 Eftimie R, Brenner HR, Buonanno A: Myogenin and MyoD join a family of skeletal muscle genes regulated by electrical activity. Proc Natl Acad Sci USA 1991;88:1349-1353.

- 35 Voytik SL, Przyborski M, Badylak SF, Konieczny SF: Differential expression of muscle regulatory factor genes in normal and denervated adult rat hindlimb muscles. Dev Dyn 1993;198:214-224.

- 36 Witzemann V, Sakmann B: Differential regulation of MyoD and myogenin mRNA levels by nerve induced muscle activity. FEBS Lett 1991;282:259-264.

37 Halter B, Gonzalez de Aguilar JL, René F, Petri S, Fricker B, Echaniz-Laguna A, Dupuis L, Larmet Y, Loeffler JP: Oxidative stress in skeletal muscle stimulates early expression of Rad in a mouse model of amyotrophic lateral sclerosis. Free Radic Biol Med 2010;48: 915-923.

- 38 Ferrari G, Cusella-de Angelis G, Coletta M, Paolucci E, Stornaiuolo A, Cossu G, Mavilio F: Muscle regeneration by bone marrow-derived myogenic progenitors. Science 1998; 279:1528-1530.

-39 Gussoni E, Soneoka Y, Strickland CD, Buzney EA, Khan MK, Flint AF, Kunkel LM, Mulligan RC: Dystrophin expression in the $m d x$ mouse restored by stem cell transplantation. Nature 1999;401:390-394.

40 Otto A, Collins-Hooper H, Patel K: The origin, molecular regulation and therapeutic potential of myogenic stem cell populations. J Anat 2009;215:477-497.

-41 Polesskaya A, Seale P, Rudnicki MA: Wnt signaling induces the myogenic specification of resident CD45+ adult stem cells during muscle regeneration. Cell 2003;113:841-852.

-42 ten Broek RW, Grefte S, von den Hoff JW: Regulatory factors and cell populations involved in skeletal muscle regeneration. J Cell Physiol 2010;224:7-16.

43 Baron P, Bussini S, Cardin V, Corbo M, Conti G, Galimberti D, Scarpini E, Bresolin N, Wharton SB, Shaw PJ, Silani V: Production of monocyte chemoattractant protein-1 in amyotrophic lateral sclerosis. Muscle Nerve 2005;32:541-544.
44 Henkel JS, Beers DR, Siklos L, Appel SH: The chemokine MCP-1 and the dendritic and myeloid cells it attracts are increased in the mSOD1 mouse model of ALS. Mol Cell Neurosci 2006;31:427-437.

45 Henkel JS, Engelhardt JI, Siklos L, Simpson EP, Kim SH, Pan T, Goodman JC, Siddique T, Beers DR, Appel SH: Presence of dendritic cells, MCP-1, and activated microglia/macrophages in amyotrophic lateral sclerosis spinal cord tissue. Ann Neurol 2004;55:221235.

46 Malaspina A, Kaushik N, de Belleroche J: Differential expression of 14 genes in amyotrophic lateral sclerosis spinal cord detected using gridded cDNA arrays. J Neurochem 2001;77:132-145.

47 Rentzos M, Nikolaou C, Rombos A, Boufidou F, Zoga M, Dimitrakopoulos A, Tsoutsou A, Vassilopoulos D: RANTES levels are elevated in serum and cerebrospinal fluid in patients with amyotrophic lateral sclerosis. Amyotroph Lateral Scler 2007;8:283-287.

-48 Tateishi T, Yamasaki R, Tanaka M, Matsushita T, Kikuchi H, Isobe N, Ohyagi Y, Kira J: CSF chemokine alterations related to the clinical course of amyotrophic lateral sclerosis. J Neuroimmunol 2010;222:76-81.

49 Zhang R, Gascon R, Miller RG, Gelinas DF, Mass J, Lancero M, Narvaez A, McGrath MS: MCP-1 chemokine receptor CCR2 is decreased on circulating monocytes in sporadic amyotrophic lateral sclerosis (sALS). J Neuroimmunol 2006;179:87-93.

50 Corti S, Salani S, del Bo R, Sironi M, Strazzer S, D’Angelo MG, Comi GP, Bresolin N, Scarlato G: Chemotactic factors enhance myogenic cell migration across an endothelial monolayer. Exp Cell Res 2001;268:36-44.

51 Griffin CA, Apponi LH, Long KK, Pavlath GK: Chemokine expression and control of muscle cell migration during myogenesis. J Cell Sci 2010;123:3052-3060.

52 Burkholder TJ, Fingado B, Baron S, Lieber RL: Relationship between muscle fiber types and sizes and muscle architectural properties in the mouse hindlimb. J Morphol 1994; 221:177-190.

53 Livak KJ, Schmittgen TD: Analysis of relative gene expression data using real-time quantitative PCR and the $2^{-\Delta \Delta C T}$ method. Methods 2001;25:402-408.

54 Merlie JP, Isenberg KE, Russell SD, Sanes JR: Denervation supersensitivity in skeletal muscle: analysis with a cloned cDNA probe. J Cell Biol 1984;99:332-335.

55 Koishi K, Zhang M, McLennan IS, Harris AJ: MyoD protein accumulates in satellite cells and is neurally regulated in regenerating myotubes and skeletal muscle fibers. Dev Dyn 1995;202:244-254.

56 Weis J: Jun, Fos, MyoD1, and myogenin proteins are increased in skeletal muscle fiber nuclei after denervation. Acta Neuropathol 1994;87:63-70.
57 Zammit PS, Carvajal JJ, Golding JP, Morgan JE, Summerbell D, Zolnerciks J, Partridge TA, Rigby PW, Beauchamp JR: Myf5 expression in satellite cells and spindles in adult muscle is controlled by separate genetic elements. Dev Biol 2004;273:454-465.

58 Kostrominova TY, Macpherson PC, Carlson BM, Goldman D: Regulation of myogenin protein expression in denervated muscles from young and old rats. Am J Physiol Regul Integr Comp Physiol 2000;279:R179-R188.

-59 Hegedus J, Putman CT, Tyreman N, Gordon T: Preferential motor unit loss in the SOD1 G93A transgenic mouse model of amyotrophic lateral sclerosis. J Physiol 2008;586: 3337-3351.

60 Pun S, Santos AF, Saxena S, Xu L, Caroni P: Selective vulnerability and pruning of phasic motoneuron axons in motoneuron disease alleviated by CNTF. Nat Neurosci 2006;9: 408-419.

-61 Chargé SB, Brack AS, Bayol SA, Hughes SM: MyoD- and nerve-dependent maintenance of $M y o D$ expression in mature muscle fibres acts through the DRR/PRR element. BMC Dev Biol 2008;8:5.

62 Hyatt JP, Roy RR, Baldwin KM, Edgerton VR: Nerve activity-independent regulation of skeletal muscle atrophy: role of MyoD and myogenin in satellite cells and myonuclei. Am J Physiol Cell Physiol 2003;285:C11611173.

63 Kosek DJ, Kim JS, Petrella JK, Cross JM, Bamman MM: Efficacy of 3 days/wk resistance training on myofiber hypertrophy and myogenic mechanisms in young vs. older adults. J Appl Physiol 2006;101:531-544.

64 Legerlotz K, Smith HK: Role of MyoD in denervated, disused, and exercised muscle. Muscle Nerve 2008;38:1087-1100.

65 Thayer MJ, Tapscott SJ, Davis RL, Wright WE, Lassar AB, Weintraub H: Positive autoregulation of the myogenic determination gene MyoD1. Cell 1989;58:241-248.

66 Lassar AB, Davis RL, Wright WE, Kadesch T, Murre C, Voronova A, Baltimore D, Weintraub $\mathrm{H}$ : Functional activity of myogenic $\mathrm{HLH}$ proteins requires hetero-oligomerization with E12/E47-like proteins in vivo. Cell 1991;66:305-315

67 Zhou J, Olson EN: Dimerization through the helix-loop-helix motif enhances phosphorylation of the transcription activation domains of myogenin. Mol Cell Biol 1994;14: 6232-6243.

68 Murre C, McCaw PS, Vaessin H, Caudy M, Jan LY, Jan YN, Cabrera CV, Buskin JN, Hauschka SD, Lassar AB, et al: Interactions between heterologous helix-loop-helix proteins generate complexes that bind specifically to a common DNA sequence. Cell 1989; 58:537-544. 
-69 Benezra R, Davis RL, Lockshon D, Turner DL, Weintraub H: The protein Id: a negative regulator of helix-loop-helix DNA binding proteins. Cell 1990;61:49-59.

70 Grimm S, Höhn A, Grune T: Oxidative protein damage and the proteasome. Amino Acids 2010, E-pub ahead of print.

$>71$ Ventadour S, Attaix D: Mechanisms of skeletal muscle atrophy. Curr Opin Rheumatol 2006;18:631-635.

72 Léger B, Vergani L, Sorarù G, Hespel P, Derave W, Gobelet C, D’Ascenzio C, Angelini C, Russell AP: Human skeletal muscle atrophy in amyotrophic lateral sclerosis reveals a reduction in Akt and an increase in atrogin-1. FASEB J 2006;20:583-585.

$>73$ Abu Hatoum O, Gross-Mesilaty S, Breitschopf K, Hoffman A, Gonen H, Ciechanover A, Bengal E: Degradation of myogenic transcription factor MyoD by the ubiquitin pathway in vivo and in vitro: regulation by specific DNA binding. Mol Cell Biol 1998;18 5670-5677.

74 Viñals F, Ventura F: Myogenin protein stability is decreased by BMP-2 through a mechanism implicating Id1. J Biol Chem 2004;279:45766-45772.

75 Glass DJ: Signaling pathways perturbing muscle mass. Curr Opin Clin Nutr Metab Care 2010;13:225-229.

$>76$ Moresi V, Williams AH, Meadows E, Flynn JM, Potthoff MJ, McAnally J, Shelton JM, Backs J, Klein WH, Richardson JA, BasselDuby R, Olson EN: Myogenin and class II HDACs control neurogenic muscle atrophy by inducing E3 ubiquitin ligases. Cell 2010; 143:35-45.
77 Dobrowolny G, Aucello M, Molinaro M, Musarò A: Local expression of mIgf-1 modulates ubiquitin, caspase and CDK5 expression in skeletal muscle of an ALS mouse model. Neurol Res 2008;30:131-136.

78 Dobrowolny G, Giacinti C, Pelosi L, Nicoletti C, Winn N, Barberi L, Molinaro M, Rosenthal N, Musarò A: Muscle expression of a local Igf-1 isoform protects motor neurons in an ALS mouse model. J Cell Biol 2005;168:193-199.

79 Figueroa A, Cuadrado A, Fan J, Atasoy U, Muscat GE, Muñoz-Canoves P, Gorospe M, Muñoz A: Role of HuR in skeletal myogenesis through coordinate regulation of muscle differentiation genes. Mol Cell Biol 2003;23: 4991-5004.

80 Kanekura K, Suzuki H, Aiso S, Matsuoka M: ER stress and unfolded protein response in amyotrophic lateral sclerosis. Mol Neurobiol 2009;39:81-89.

81 Chang Y, Kong Q, Shan X, Tian G, Ilieva H, Cleveland DW, Rothstein JD, Borchelt DR, Wong PC, Lin CL: Messenger RNA oxidation occurs early in disease pathogenesis and promotes motor neuron degeneration in ALS. PLoS One 2008;3:e2849.

82 Kawai T, Fan J, Mazan-Mamczarz K, Gorospe M: Global mRNA stabilization preferentially linked to translational repression during the endoplasmic reticulum stress response. Mol Cell Biol 2004;24:67736787.

83 Kong Q, Lin CL: Oxidative damage to RNA: mechanisms, consequences, and diseases. Cell Mol Life Sci 2010;67:1817-1829.

84 Chen JF, Tao Y, Li J, Deng Z, Yan Z, Xiao X, Wang DZ: microRNA-1 and microRNA-206 regulate skeletal muscle satellite cell proliferation and differentiation by repressing Pax7. J Cell Biol 2010;190:867-879.
85 Williams AH, Valdez G, Moresi V, Qi X, McAnally J, Elliott JL, Bassel-Duby R, Sanes JR, Olson EN: microRNA-206 delays ALS progression and promotes regeneration of neuromuscular synapses in mice. Science 2009;326:1549-1554.

86 Sweetman D, Goljanek K, Rathjen T, Oustanina S, Braun T, Dalmay T, Munsterberg A: Specific requirements of MRFs for the expression of muscle specific microRNAs, miR-1, miR-206 and miR-133. Dev Biol 2008; 321:491-499.

87 Kitzmann M, Carnac G, Vandromme M, Primig M, Lamb NJ, Fernandez A: The muscle regulatory factors $\mathrm{MyoD}$ and $\mathrm{Myf}-5$ undergo distinct cell cycle-specific expression in muscle cells. J Cell Biol 1998;142:14471459.

88 Lindon C, Montarras D, Pinset C: Cell cycleregulated expression of the muscle determination factor Myf5 in proliferating myoblasts. J Cell Biol 1998;140:111-118.

89 Miller RJ, Banisadr G, Bhattacharyya BJ: CXCR4 signaling in the regulation of stem cell migration and development. J Neuroimmunol 2008;198:31-38.

90 Ratajczak MZ, Majka M, Kucia M, Drukala J, Pietrzkowski Z, Peiper S, Janowska-Wieczorek A: Expression of functional CXCR4 by muscle satellite cells and secretion of SDF1 by muscle-derived fibroblasts is associated with the presence of both muscle progenitors in bone marrow and hematopoietic stem/ progenitor cells in muscles. Stem Cells 2003; 21:363-371. 